\section{The Impacts of Consumptive Behaviors toward American Society in Modern Era as Reflected in the Film The Joneses}

\author{
1 Ambarwati Budi Rahayu \\ 2 Nadella Lesmana \\ 3 Didik Murwantono
}

123 Universitas Ahmad Dahlan, Indonesia

\begin{abstract}
\section{Keywords}

American society

consumptive behavior

modern era

impacts

The Joneses
\end{abstract}

In this research, the writers make research of consumptive behavior and its impacts. "The Joneses" film represents the impacts of consumptive behavior in American society in many aspects of life. The objective of this paper is to describe and find the impacts of consumptive behavior toward American society, as reflected in the film "The Joneses." In analyzing data, the writers use a qualitative method by gathering the data qualitatively. The result reveals kinds of consumptive behavior, factors of consumptive behavior, impacts of consumptive behavior, and things that influence consumptive behavior. Some of them are environment and internal motivation.

\section{Ethical Lingua}

Vol. 7, No. 1, 2020

ISSN 2355-3448 (Print)

ISSN 2540-9190 (Online)

Corresponding Email Ambarwati Budi Rahayu am.budi89@gmail.com

Article's History

Submitted 2 February 2020

Revised 9 April 2020

Accepted 9 April 2020

DOI

10.30605/25409190.154

Copyright (๑) 2020

The Author(s)

This article is licensed under CC BY-NC-SA 4.0 License

\section{(cc) EY-NC-SA}




\section{The Impacts of Consumptive Behaviors toward American Society in Modern Era as Reflected in the Film The Joneses}

When we talk about consumptive behavior, it is about shopping for unimportant things. What is called consumptive behavior cannot be separated from materialism. The meaning of consumptive is spending money on unimportant things just for lifestyle. Behavior cannot be separated from attitudes. Freedman stated that changes in attitudes produce corresponding changes in behavior. When a politician tries to persuade a voter to have appositive attitudes toward him, he is not doing this just because he wants to be liked, he wants a vote. He assumes that the more the voter likes him, the more probable it is that he would vote for him. Changing an attitude is one way of changing behavior. It is, therefore, important to determine whether attitudes do affect behavior and whether the two are always consistent (Freedman, 1968: 347).

America, with its intelligence, has been successful in its country. There are many aspects that America has been successful such as politics, economic, military, entertainment industries, information systems, sport, technology, and many industries. All of the above aspects influence the American lifestyle. We can see from the economic aspect; there are many company industries in America. They have completed each other to get their profit. McCracken (1987) notes that:

"Conspicuous and competitive consumption is especially important to the study of the history of consumption because they play such an important role in the growth of a consumer society" (p. 50).

They have produced many various things. They always try to get something new to collect the buyer. They promote their product attractively. They design their products well. It is a perfect thing. So, the buyer is interested in looking at those things. The buyer tries to get the industry's product because they want to perfect life with the company product. They think that wearing good brand things, they look good and perfect. They become consumptive. Shopping makes them consumptive. They do all the things to get the things that they want. It makes an impact on American society. It can be studied continuously along with the passage of time, place, and social condition.

There are many factors and conditions of a person that later become motivations for doing something. There must be motivations that occur inside of consumptive lifestyle. This is understood to be the most important part of the analysis to make us understand what factors behind their lifestyle. Knowing their motivations can help us to learn about their life then we can avoid the impacts. Brown (1992) states,

"The changes in behavior following the manipulation of motivational concepts." Moreover, we have stressed the view that any experiment purporting to demonstrate motivational effects is not convincing unless the influence of other factors has been eliminated or controlled. Altering a so-called motivational variable may indeed modify drive strength; but it may also lead to changes in the intensity and kinds of affective stimuli, in the degree of learning, or in the physiological condition of the organism. Whenever variations in factors 
such as these provide acceptable explanations for the observed behavior the concept of the drive may become expendable." (p. 37)

Besides the wrong side of their life, they also got the right side. Consumptive behavior made good contributions to American industries that help the government to do their job. In this paper the writerss will discuss the impact of consumptive behavior toward American society because consumptive behavior appeared in American society and it is a subculture that appeared in America. It has an impact on American society.

In this study, pop culture as a part of American Culture. Popular culture characters are written or transmitted by print broadcasting, or another commercial, not the serious concept and idealism individual word mass-produced to give pleasure, financial aims and popularity become the goals, patented and in the form of pop lit, pop song, pop art.

Related with the information above, the writers thinks that The Joneses film is an example of a film that describes the impact of consumptive behavior toward American Society. So, the writers decided that The Joneses is interesting to be discussed. There are reasons why the writers wants to conduct research on the film The Joneses by Derrick Borte. The Joneses is a good film because, from the plot, the condition of American Society is described.

\section{Method}

In this research, there are main data and supporting data. The main data are taken from The Joneses film by Derick Borte, which is distributed by Universal Picture 06/05 Feature Film. To get the data, the writers employ library research. The writers go to the library and read some graduating papers which has correlation with the subject to find out information. The writers also go to the internet to look for more information about the topic that the writers choose. The writers also watch the film The Joneses for many times in order to understand the story of the film.

In analyzing data, the writers use qualitative research. It means, to describe the phenomenon must be detailed and by some process to get the relevant data qualitatively. The descriptive technique is a way used in this research to get more explicit information about the data that deal with the topic. There are some steps to processing the data. First, watching the film The Joneses for several times, second, arranging the data, and the third is synchronization between the data and the theories.

\section{Results}

\section{Kinds of consumption}

The writers have found four kinds of consumptive behavior in this film. It can see from Table 1. There are four kinds of consumptive behavior. The first is direct consumption. It can see from they eat delicious and famous food from famous catering. The second is productive consumption, it can see from Steve drives a new Audi R8 that is very expensive. The third is uneconomical consumption, we can see from Steve and Kate try to offer very expensive food through the party. The fourth is a dangerous consumption. It can see from Mick and Tim have special and interesting things. It is very popular for young adult, but it is dangerous. 
Table 1. Kinds of consumption in The Joneses Film

\begin{tabular}{llll}
\hline Direct Consumption & Productive consumption & $\begin{array}{l}\text { Uneconomical } \\
\text { consumption }\end{array}$ & Dangerous consumption \\
\hline $\begin{array}{l}\text { They eat delicious and } \\
\text { expensive food from } \\
\text { famous catering. }\end{array}$ & $\begin{array}{l}\text { Steve drives a new Audi } \\
\text { R8. It is very expensive. }\end{array}$ & $\begin{array}{l}\text { Steve and Kate try to } \\
\text { offer very expensive } \\
\text { food through the party. }\end{array}$ & $\begin{array}{l}\text { Mick and Tim have } \\
\text { special thing. It is } \\
\text { dangerous thing. But, it } \\
\text { is popular. So, they like } \\
\text { it. }\end{array}$ \\
\hline
\end{tabular}

\section{Factors that cause consumptive behavior}

Table 2. Factors that cause consumptive behavior

\begin{tabular}{ll}
\hline External factor & Internal factor \\
\hline $\begin{array}{ll}\text { Summer and Larry give a gift to the new neighbor } \\
\text { in front of their house. It is a tradition in America. }\end{array}$ & $\begin{array}{l}\text { The motivation that they want to have a perfect life } \\
\text { and they compete with each other. }\end{array}$ \\
$\begin{array}{l}\text { They always give a gift to a newcomer, such as a } \\
\text { new friend, neighbor, or their family that come from } \\
\text { distant places. }\end{array}$ \\
\hline
\end{tabular}

The writers has found factors that cause of consumptive behavior. It can see from Table 2 above. There are two factors. The first is external factor and the second is internal factor. It can see the external factor that cause of consumptive behavior from this film when Summer and Larry give a gift to the new neighbor. It is a tradition in America. They always give a gift to a new comer. It can also see the internal factor from this film. The motivation is the internal factor here. The motivation that they want to have a perfect life and the compete each others.

\section{The impacts of consumptive behavior as reflected in the film The Joneses}

Table 3. The impacts of consumptive behavior

\begin{tabular}{ll}
\hline No. & Impacts \\
\hline 1. & Hedonist lifestyle \\
2. & Consumerism \\
3. & Extravagance \\
4. & Impulsive \\
5. & Credit card debt trapping \\
6. & Depression \\
7. & The false perspective about life \\
8. & Materialistic \\
\hline
\end{tabular}

The writers have found the impacts of consumptive behavior in American society, as reflected in this film. It can see from Table 3 above. There are eight impacts of consumptive behavior. 
There are hedonist lifestyle, consumerism, extravagance, impulsive, credit card debt trapping, depression, the false perspective about life, and materialistic. All of the impacts those impacts are reflected in "The Joneses" film.

\section{Discussion}

\section{Kinds of consumption}

There are four kinds of consumption. That is direct consumption, productive consumption, uneconomical consumption, and dangerous consumption. In the film The Joneses, the kind of consumption which can be found is productive consumption because this film has variety product of use, such as clothes, curtains, bedsheets, pillowcase, and other branded things.

The first kind is direct consumption. Direct consumption is consumption that directly answers the needs of a person. For example, people need medicine as soon as possible when he was sick. In The Joneses, the writers cannot find direct consumption because in this film nothing important action that needs the direct consumption.

The second is productive consumption. Productive consumption is a product that has variety of use. In productive consumption, there is always innovation. In productive consumption, there is good and bad consumption. The good consumption is when we consume products which are useful for us. It suits our needs. Moreover, bad consumption is the things that we buy are not suitable for our needs. The Joneses includes productive consumption because they always follow innovation. They are always stylish in their performance. They always wear new brand things. Such as clothes and bedsheets. It can be seen from the quotation below:

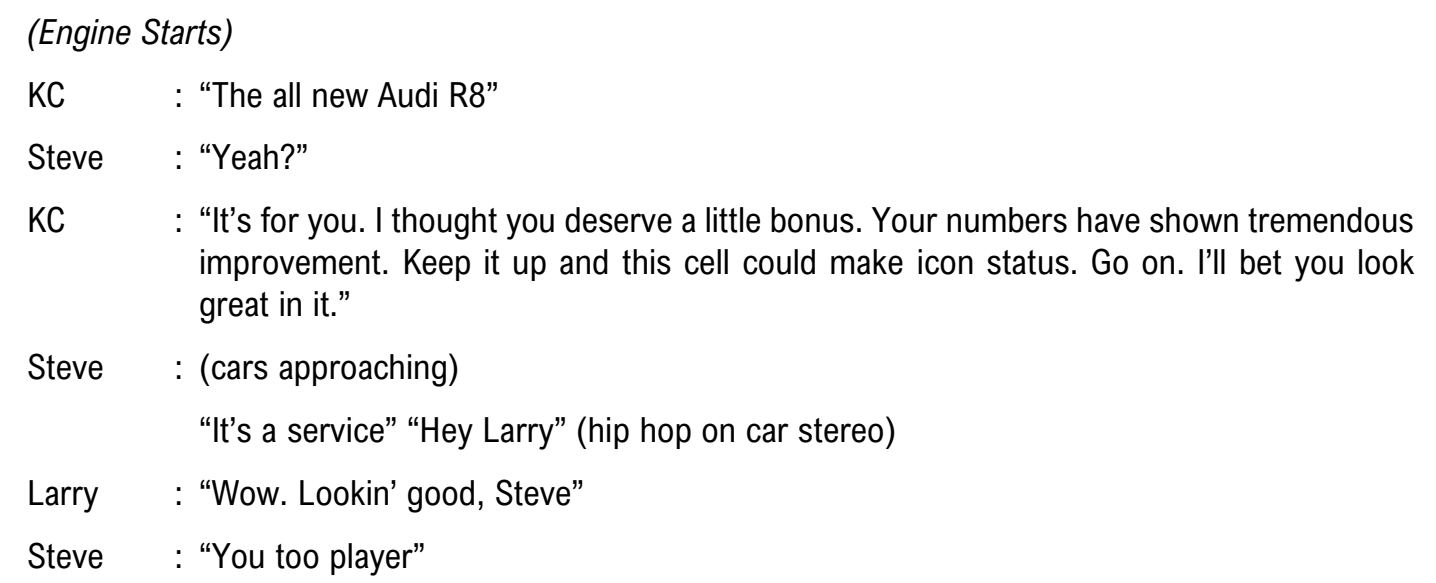

(Taken from film The Joneses)

From the quotation above, Steve gets the new Audi R8 car from his boss because of his good works. Audi R8 is a new brand car. It can be considered as a good productive consumption because it is bought to be given as rewards for a good employer. It will stimulate the employer to work harder. Although the example above is good productive consumption, the writers can find the aim of KC. KC wants Steve to ride that car in order to be good looking in his neighbors. Furthermore, his neighbors will be interesting in Steve's car and buy it although the price is so expensive.

The other example of productive consumption is that Kate changes her toilet with the toilet that has sophisticated technology. Kate uses the toilet with sophisticated technology. That toilet called Toto. It makes it easy for her and all of the users because the toilet washes and 
dry automatically dry. It is very comfortable. The toilet seat rose up and waved. It makes life easy. It was the other example of good productive consumption. The third is uneconomical consumption. Uneconomical consumption is consumption that does not answer the need of an individual. Uneconomical consumption is using all of the things to unimportant things.

The fourth is dangerous consumption. Dangerous consumption is consumption that harms an individual. It is very dangerous for our body. Dangerous consumption can disturb our health. It also can damage our bodies. The example of dangerous consumption is drinking alcohol, using drugs, etc. Alcohol can damage organs of our body. Maybe, we do not realize that alcohol damaged our body gradually. The damage depends on how much we drink alcohol. If we are drinking a few of alcohol, it just disturbs our health. If we are drinking too much alcohol, it can damage the organs of our body. The alcohol can damage or disturb our brain, our eyes, and many others. Drugs are more dangerous than alcohol. Drugs can be addictive. It is because drugs contain many of chemical material. Drugs make our body unconscious. So, what we have done sometimes is not suitable with our mind. The people that often consume drugs will be addicted and they cannot do something without drugs. Both alcohol and drugs are dangerous.

In The Joneses, the writers can find the example of dangerous consumption. Mick and Tim came in drinking party. They drank alcohol and used drugs. Drugs make them imagine about ride racer. So, after they came in the drinking party, they ride a car with uncontrolled rapidity. They ride Mick's new car. At the night, Mick just drank a few of alcohol. So, he is still conscious that it is so fast and he gave Tim a signal to stop. But, they are too drunk to realize the danger. We can see from dialogue below:

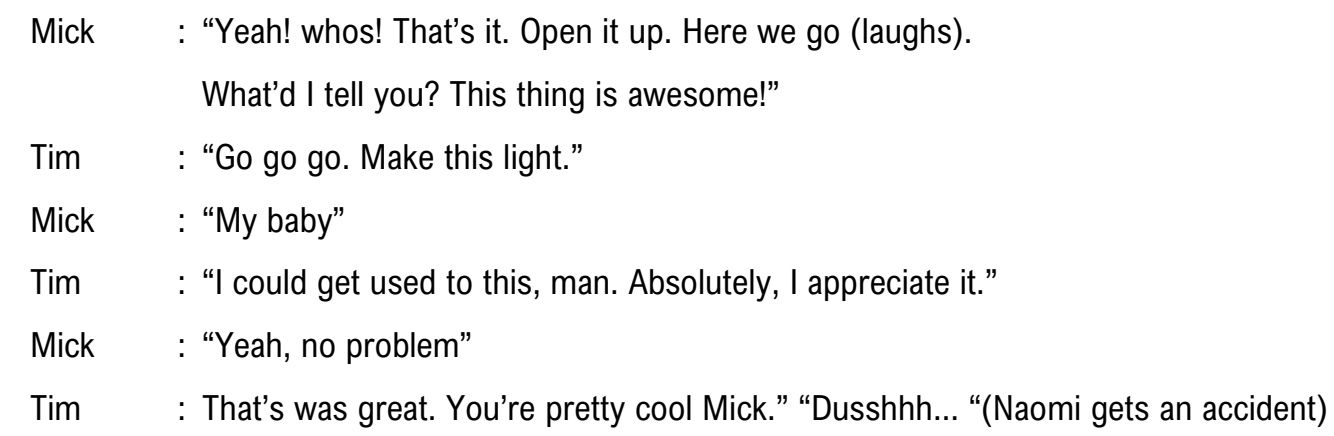

(Taken from film The Joneses)

Rechtshaffen (2011) wrote a review entitled "Consumption isn't the only conspicuous in this unsubtle satire". He states that,

"A self-satisfied satire about a quartet of salespeople posing as your average affluent American family, The Joneses certainly had a workable premise at its disposal. The film can't help but draw comparisons to Confessions of a Shopaholic, another ill-timed comedy about raging consumerism that few found funny given the current economic climate." (Consumption isn't the only conspicuous in this unsubtitle satire, 2011, par. 2)

The other review is the essay by Panelo (2011) entitled "Stealth marketing and bland brands: Lessons from The Joneses". The Joneses may have a deeper lesson for brands: the homogenizing effects of keeping up with the competition. In the film, everyone lives in the same McMansions and uses the same golf clubs, cars and caterers. He stated that:

"Brands themselves are stuck on a hyper-competitive treadmill, this can homogenize product marketing and make brands look blandly similar." (p. 2) 


\section{Factors that cause of consumptive behavior}

External factors that influence consumptive behavior include cultural, social class, reference group, and family. In this discussion, the writers finds the cultural and social class influences the consumptive behavior of the characters. Culture consists of patterns, explicit and implicit, of and for behavior acquired and transmitted by symbols, constituting the distinctive achievement of human groups, including their embodiments in artifacts; the essential core of culture consists of traditional ideas and especially their attached values; culture system may, on the one hand, be considered as products of action on the other as conditioning elements of further action.

Culture encompasses the set of beliefs, moral values, traditions, language, and laws (or rules of behavior) held in common by a nation, a community, or other defined group of people. In America, visiting a new friend or family member, especially from another village or town, bringing a gift as a gesture of gratitude for something is typically a warm and really welcome. It is always done by American people. The habitual action giving a gift is not only when they find a new friend or family members, but also, they give a gift to their loving people. It is as a gesture of gratitude for something, such as, to express their endearment and thankful. Because of they always do it, so, it becomes a culture in America.

The culture world around us our attitudes, habits and actions how we act and why we act, we wear, our buildings, our roads and means of ravel, our entertainment, our politics, sport, religion, medical practices, our belief and activities and what shapes and control them. It is other words to us water is to fish. The writers can find it is from The Joneses. We can see from the dialogue below:

Summer : "Um, we're the Symondses from next door. I'm Summer, and this is my husband Larry. I just wanted to bring you this welcome gift."

(Taken from film The Joneses)

From the dialogue above, we can see that summer and Larry give a gift to the new neighbor in front of their house. It is a tradition in America. They always give a gift to a newcomer, such as a new friend, neighbor, or their family that come from far places.

The other external factor that cause of consumptive behavior is social class. Social class is an arrangement which is a relatively permanent and regular basis in a society whose member value, attention, and behavior that tends to the same. Social class is one of a cause of consumptive behavior. We can see their social class from their lifestyle. We can see from the quotation below:

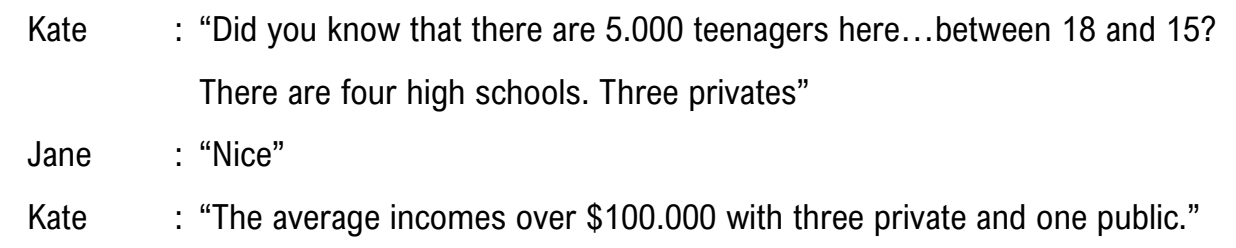

(Taken from film The Joneses)

From the dialogue above, we can see that in film The Joneses the characters belong to middle class. They live in elite area and their incomes are over $\$ 100,000$ a year. In America, surveys have shown that, while people consider $\$ 40,000$ a year to be the low end of what it takes to buy a middle-class life, some people who make as much as $\$ 200,000$ a year still consider 
themselves middle class, the researchers said. So, it can be concluded that the people that have income $\$ 40,000$ until $\$ 200,000$ is middle class. But, sometimes it also depends on their life maybe with many children, populations, and their necessity.

Beside the external factor, there is the internal factor that cause of consumptive behavior. The internal factor that cause consumptive behavior includes motivation, perception, learning, economic circumstances, personality, self-concept, and lifestyle. The writers finds the motivation and lifestyle as the internal factors.

Motivation is literally the desire to do things. It's the difference between waking up before dawn to pound the pavement and lazing around the house all day. It's the crucial element in setting and attaining goals - and research shows you can influence your own levels of motivation and self-control. So figure out what you want, power through the pain period, and start being who you want to be.

In film The Joneses the motivation is they want to have perfect life and they compete each other's. In this film, summer wants to be a powerful salesperson. She wants to be better than the Joneses. Billy wants to show the new bag brand called YSL. He supposes that YSL cannot be found in around here. YSL is symbol of style. He always followed the style because he has salon that is identical with lifestyle. He always updated about trend. He knows about branded things that his costumer like. So, he always gives his customer information about what is the trend today. By his information, his customers buy that product. They want to get the perfect performance and stylish in every season.

Actually, they do not need that thing because trend is changing in every time. But, they want to get good performance. They change their style every time. They change their style when they are finding a new thing. And they leave their branded things before. It is such a waste. It is also one of consumptive behavior.

Mulyani, Thomas, \& Wiidiyanto (2018) have found that the factor that influences consumption is attitude. So, here attitude also influences the consumption. Lifestyle was also in the middle category that influences consumption Furthermore, by Enrico \& Oktavia (2014) have found that prestige is also factor that influences consumptive behavior. Prestige is one of important thing for some people. They will be satisfied with a good thing around them because they have prestige. Moreover, Nugroho (2010) said that that lifestyle reflects the real problem that exist in customers' who tend to blend and share things related to consumer psychological emotion problems.

\section{The impacts of consumptive behavior as reflected in the film The Joneses}

\section{Hedonist lifestyle}

One impacts of consumptive behavior is hedonist lifestyle. Hedonism is a glamorous style or pleasure. In this case, the people try to pour something with how they were wearing clothes. One of hedonist lifestyle to pursue of pleasure is with glamorous life, in order to get the attention from the people. The basic idea behind hedonistic thought is that pleasure is the only thing that is good for a person. This is often used as a justification for evaluating actions in terms of how much pleasure and how little pain they produce. In very simple terms, a hedonist strives to maximize this total pleasure (pleasure minus pain). 
Consumptive in fashion is one of American woman behaviors to create an image to perform their social and personal identity, especially to American woman. It shows from Kate carries out the party. She carries out that party just to welcome party to their neighbors because they are a newcomer in that area. Kate also introduces the luxurious and branded things that they have consumed in that party. She invited her friends. She serves the best of food and soft drinks that cannot be found in her city. She made them delivered from Antarctica and Mexico. This is a far place. And she also orders from a famous catering. She wants to show that she can carry out the best party. And it makes her pleasant and satisfied.

\section{Consumerism}

Another problem of American people, especially woman is about her consumerism lifestyle. Consumerism is the equation of personal happiness with consumption and the purchase of material possessions. Consumptive is included identity. It is something that is shared and is susceptible to the influence of the global market. Market researchers, politicians, and those interested in people's values now benefit from understanding the changing nature of individuals' identities. Identity influences lifestyles and determines everything from the clothes people wear to the leisurely activities they enjoy. Because consumer preferences allow people to identify with others making similar choices, changes in identity are accompanied by new patterns of consumer behavior. (American Mosaic, 2011, par 2).

It shows from Charlie wants to take a credit to buy a new stick to play golf. He wants to buy it because the stick has a nice shoot. He wants to be a good player because he follows the club golfer. Actually, he has many of sticks to play golf. But, he is always updating on golf merchandise.

\section{Impulsive}

Impulsive is our willingness from our heart. It happened spontaneous from our heart. This aspect indicates that an adolescent to behave solely because it is based on the sudden passion and desire for a moment, done without any form of consideration, not to think about what will happen, and emotional. In The Joneses, the writers find from the golfer club. They pursue the polarized lenses.

It can be seen that the golfer is seeing the polarized lenses in the merchandise golf shop. They can't stop talking about that thing. They are very interesting with those lenses. So, they buy that lenses without a long think. They feel confident to play golf by using that lenses. Actually, they have many lenses to play golf. But, they pursue the polarized lenses. They think that the polarized lenses are more sophisticated than their lenses before.

\section{Extravagance}

One of the most prominent indicators of this aspect is exaggerated. Besides this aspect describes the consumer behavior as a behavioral buying that squandering lots of money without a clear based on the need. Extravagance likes glamorous things and spending money to useless thing. In this film, Kate and her husband held a luxurious party in her home with all of branded things from clothes, jewelry, famous beer, famous cake, famous chef catering, and others.

It shows that Kate wears good branded earrings, although it is not special day. She also offers the kinds of food, soft drinks, and catering from the best brand. Kate is satisfied by wearing 
her new earrings from Steve. She wants to get attention from the people in the party. She also hires a famous chef. It is a great satisfaction to her.

Rizkallah \& Truong (2010) have found that Hispanics prefer to shop in an actual store and after can be followed by online shop as a second choice. It is different with this research, they try to offer their things by wearing the things that they want to sell and also they use online promotion.

\section{Credit card debt trapping}

Credit card is kind of payment. Most of American people have a credit card. This is the simple payment. Usually they use credit card to shopping, business, and many others payment. But, this became problem if no income in our bill. We can get debt from bank. We must pay that debt. Debt Trap is a situation where you add on a new debt in order to pay an existing debt. Generally, when the firm in overleveraged all the credit sources are exhausted, firm arrives at a situation of debt trap. (The credit card dept trap, 2011, par.1)

In The Joneses, because of their consumerism behavior, the character Summer and Larry get debt from bank. It is shown that Larry and Summer have too much debt in bank. They cannot pay their bills. They get debt in bank because they want to be like the Joneses. All of things in the Joneses are branded with the perfect family. Their credit card has been declined. Dunn \& Mirzaie (2012) have found that debt is obviously a problem for many American household in both economic and psychology. They have found that both of male and female have debt trapping.

\section{Depression}

Depression is something like confused or worried about something. Depression occurs because the people are confused to overcome the problem in their life. In American society, many of people get depression. It is because they want to have perfect life. In this film, The Symonds wants to be like the Joneses. They buy all of things that The Joneses have. They are depressed because they have debt in bank and they cannot pay it. So, they are confused to overcome their problem because credit card is very important for their business. In this film, Larry killed himself in the swimming pool. We can see the dialogue below:

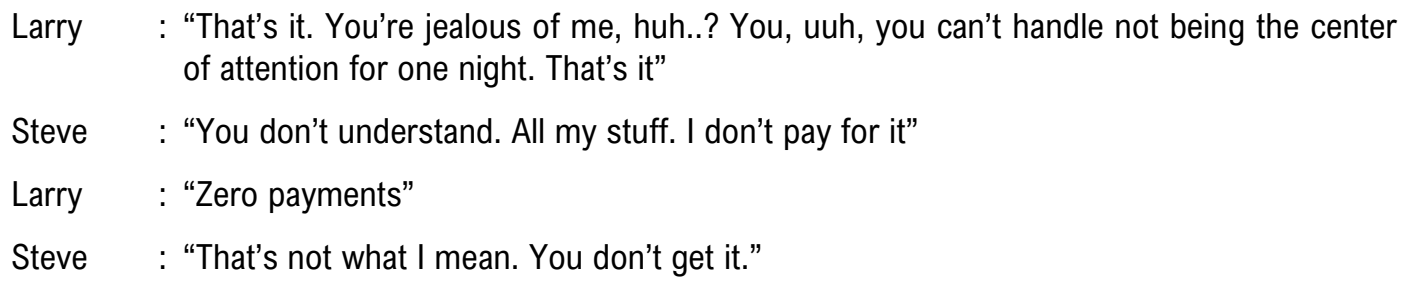

(In the morning after the party)

Summer : "What the ...Larry? Larry? Larry!" (Summer crying). Help! Help!"

(Steve comes on)

$\begin{array}{ll}\text { Steve } & : \text { :Call } 911 ! \text { !'Larry die) } \\ \text { Man } & : \text { :Hey, you did everything you could" } \\ \text { Steve } & : \text { :No, I didn't. I lied to him" } \\ \text { Kate } & : \text { :Here's your coat" }\end{array}$


From the dialogue above, it can be concluded that Larry is depressed because of dept trapping. He cannot pay it. He wants to be like the Joneses that have all of things. But, he falls into debt trapping. He cannot solve the problem. Finally, he killed himself. He sinks himself in the swimming pool.

\section{The false perspective about perfect life}

Perfect life is the intension of every people. Every people that see the Joneses will think that is the real perfect life. They want to be the Joneses who have a complete family. The Joneses have all of things. They have a complete family, the beautiful wife, son and daughter, good house, good car, good clothes, and all of branded thing. So, every people want to be like the Joneses. That is what the neighbors see in the Joneses family. So, they want to be like them. But, it is just imagination in The Joneses. They don't know that it is not real. The Joneses is not a real family. We can see from the dialogue below:

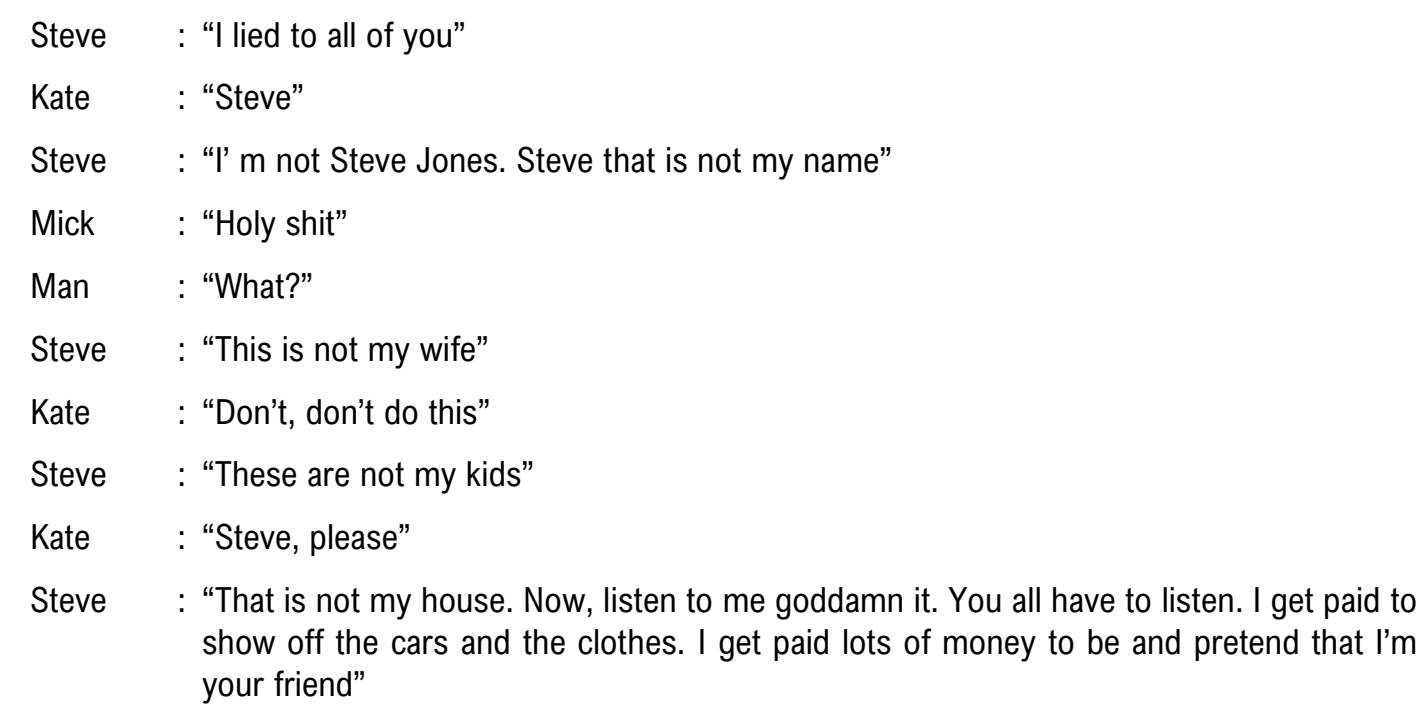

(Taken from film The Joneses)

From the dialogue above, all of people think that the Joneses are the real family. The Joneses have a complete family. Their house is full of luxurious branded things. Their clothes is stylish. Their car is always new. Their phones are sophisticated technology. But, it is not true. They just a family rented by famous company. So, the perfect life that becomes imagination in the Joneses is nothing.

\section{Materialistic}

Materialistic is the belief that only money that is important. It is just material and physical comforts. They believe that material are all that matter in life. So, it is often associated with money because all of things need money. Materialistic is the phenomena in our society because it has relationship in our everyday life. We can get things that we need with money.

The people get many advertising messages from their car radios, televisions, smart phones and computers. It comes from co-workers, friends, neighbors and family members. Therefore, in this film, the power of influence on the buying habits of Americans is described in The Joneses. In this film, they are hired as individuals and then put together as a family to 
stay in a wealthy area to buy as many of the latest luxury brand name clothes, appliances, technology, home decor, food and sporting goods as possible.

They accomplish it by wearing and displaying the goods to neighbors, friends, family and anyone they come across in their daily lives. The Joneses not only have the top of the line products, but they are terrific and make them want what they have. The Joneses is a decent film that described about materialism and the consequences in real life. We can see the example from the dialogue below:

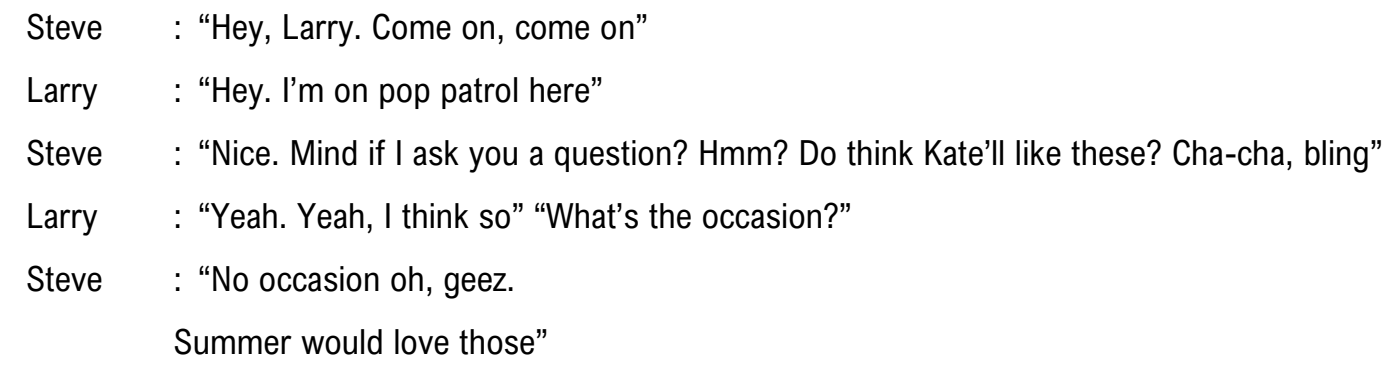

(Taken from film The Joneses)

From the dialogue above, Steve shows the jewelry to Larry. The jewelry is to Kate. Steve makes sure that it is pretty cha-cha bling. It is a luxury brand. Steve is sure that Larry also wants to make his wife glad. So, he shows it to Larry. But, Steve says that it is good to make business. All of things need money. Without money Larry cannot buy it. Research by Durvasula \& Lysonski (2010) have found that young Chinese regard money as a source of power and prestige. So, everything is measured by using money. It has important relationship with materialistic.

\section{Conclusion}

Based on previous discussion, the writers comes to the conclusion that consumptive has many impacts in life. The consumptive behaviors in The Joneses film are some of the most events that happened in American society. It happens because of environment and internal motivation. Consumptive behavior is a phenomenon in our life. It can be given an advantages and disadvantages to our life. The advantages of consumptive behaviors are the increase of income companies. But, the increases or decreases of incomes depend on the company strategy.

There are four kinds of consumption. They are direct consumption, productive consumption, uneconomical consumption, and dangerous consumption. Those four consumptions become our consumption. It makes us consumptive. The first kind is direct consumption. The second is productive consumption. Productive consumption is a product that has variety of use. In productive consumption there is always innovative. In productive consumption there is good and bad consumption. The third is uneconomical consumption. Uneconomical consumption is consumption that does not answer the need of an individual. The fourth is dangerous consumption. Dangerous consumption is consumption that harms an individual. It is very dangerous for our body. Dangerous consumption can disturb our health. It also can damage our body.

In conclusion, consumptive is a part of behavior and relationship with our daily life. It is because consumptive can also give enjoyment. Consumptive is one of the many elements of society behavior, the unique form of how we spend our money to unimportant things. The 
writers assumes that, consumptive has many impacts toward American society. It can be seen from The Joneses film. Based on the research on The Joneses film, the writers can see clearly that has many impacts toward American society, such as hedonist lifestyle, consumerism, impulsive, seeking pleasure, extravagance, credit card dept, trapping, depression, the false perspective about perfect life, and materialistic.

The implication from this research is the consumptive behavior happens because of environment and internal motivation. Everyone likes to see something nice, branded, and popular. They also like to see someone that is good looking with everything around him. So, it depends on individual how they can control their interest in everything. If they can control themselves, they can also manage their life.

The writers suggests that we must avoid consumptive behavior. It is a kind of phenomenon in our life. It can be bad and good. It is depend on manage it in our life. We must be adjusted all of things with our needed. In this film, the people do all of things to get the luxury and branded things. After we know about impacts of consumptive behavior above, the writers hopes that we can be avoided from those impacts. The further research about how to avoid consumptive behavior is very necessary.

\section{Acknowledgment}

$\mathrm{N} / \mathrm{A}$

\section{References}

Brown, J. S. (1961). The Motivation of Behavior. New York: McGraw Hill

Durvasula, S., \& Lysonski, S. (2010). Money, Money, Money - How Do Attitudes toward Money Impact Vanity and Materialism. Journal of Consumer Marketing, 27. pp. 169179.

Dunn, L. F., \& Mirzaie, I. A. (2012). Determinants of Consumer Debt Stress: Differences by Debt Type and Gender. Department of Economics: Colombus, Ohio State University.

Enrico, A., \& Oktavia, O. (2014). The Factors that Influenced Consumptive Behavior: A Survey of University Students in Jakarta. International Journal of Scientific and Research Publication 4(1).

Freedman, J. L. (1968). Social Psychology. Columbia University

McCracken, G. (1987). The History of Consumption: A Literature Review and Consumer Guide. Journal of Consumer Policy, 10, pp. 139-166.

Mulyani, R., Thomas, P., \& Widiyanto, W. (2018). The Influence of Student Consumption, Social Status of Family, The Economic Parent Status, and The Economic Education of Family to Consumption Behavior. Journal of Economic Education, 7(1). https://doi.org/10.15294/jeec.v7i1.22190

Nugroho, S. (2010). Perilaku Konsumen. Jakarta: Kencana Prenanda Media Group.

Smith, H. N. (1980). Can American Develop a Method?: Studies in American Culture. Ed. Panelo, S. (2011). Stealth marketing and bland brands: Lesson from The Joneses.

Rizkallah, R. \& Truong, T. (2010). Consumptive Behavior, Promotional Preferences, and Shopping Patterns of Hispanic Americans: An Empirical Perspective. USA: La Sierra University.

Rechtshaffen, M. (2011). Consumption isn't the only conspicuous in this unsubtle satire 